\title{
Atresia revisited: two basic patterns of atresia of bovine antral follicles
}

\author{
H. F. Irving-Rodgers ${ }^{1}$, I. L. van Wezel ${ }^{1}$, M. L. Mussard ${ }^{2 *}$, \\ J. E. Kinder ${ }^{2 *}$ and R. J. Rodgers ${ }^{1+\neq}$ \\ ${ }^{1}$ Department of Medicine, Flinders University of South Australia, Bedford Park, \\ SA 5042, Australia; and ${ }^{2}$ Department of Animal Sciences, University of Nebraska, \\ Lincoln, NE 68583, USA
}

Our observations of bovine follicles indicated that the original histological classifications of atresia were inaccurate. A detailed histological, ultrastructural and immunohistochemical study of antral follicles from bovine ovaries collected from an abattoir and from animals whose large follicles had been monitored by ultrasonography was conducted to investigate this further. Nidogen and CD68 were immunolocalized to observe the follicular basal lamina and macrophages, respectively. In randomly collected ovaries, approximately one quarter of all antral follicles were undergoing antral atresia, as designated in this study. Antral atresia was characterized by early destruction of the layers of the membrana granulosa closest to the antrum, whereas the most basal cells remained intact. Numerous pyknotic nuclei were observed in the most antral layers and in the antrum close to the membrana granulosa. This is the classic description of atretic follicles and was observed at all sizes of follicle development and almost universally in large follicles (> $5 \mathrm{~mm}$ in diameter), including dominant follicles. Basal atretic follicles, as designated in this study, were almost as prevalent as the antral atretic follicles, and were characterized by initial destruction of the most basal layer of granulosa cells, whereas the cells in the most antral layers remained associated with each other and were predominantly healthy. Pyknotic nuclei and the nuclei of dying basal cells budded into apoptotic bodies were observed rarely. The basal lamina of basal atretic follicles was often breached by macrophages, which were phagocytosing dying basal granulosa cells. The theca was characterized by an increased deposition of collagen, and the cells were orientated randomly, rather than lying parallel to the membrana granulosa as in healthy follicles. Basal atresia occurred in small $(<5 \mathrm{~mm}$ in diameter) follicles only. Importantly, these basal atretic follicles were originally identified incorrectly in the literature. Thus, on the basis of the results of this study and another on the expression of steroidogenic enzymes in atretic follicles, it is suggested that the standard biochemical methods for measuring steroid hormone concentrations in follicular fluids to assess atresia should be re-evaluated.

\section{Introduction}

In mammalian ovaries, eggs develop within follicles. At birth, bovine ovaries contain several hundred thousand primordial follicles; however, $<0.5 \%$ of these follicles ever reach maturity with eggs being ovulated; the remainder undergo atresia and regress. Morphological and endocrine criteria have been used to identify atretic follicles. Morphological analysis is more useful as it can be used for smaller follicles, which have not reached sufficient size to contain cytochrome P450 aromatase. In almost all studies to date, the morphological feature used to classify antral follicles as atretic was the presence of pyknotic nuclei

*Present address: Department of Animal Sciences, The Ohio State University, Columbus, OH 43210-1095, USA

+Present address: Reproductive Medicine Unit, Department of Obstetrics and Gynaecology, Adelaide University, Adelaide, SA 5000, Australia (shrunken nuclei staining strongly with haematoxylin and indicative of cell death) in the membrana granulosa or antrum (Byskov, 1978; Hirshfield and Midgley, 1978; Kruip and Dieleman, 1982; Blondin et al., 1996). A reduced number of mitotic nuclei is also an accepted indication of early stage atresia (Kruip and Dieleman, 1982). Eventually the whole membrana granulosa and cumulus are destroyed. Resorption of the follicular fluid and destruction of the oocyte are comparatively late events in atresia (Greenwald and Terranova, 1988). The close relationship between granulosa cell death and follicular atresia has led to intense investigation of the mechanisms by which granulosa cells die (Hughes and Gorospe, 1991; Jolly et al., 1994; Palumbo and Yeh, 1994; Derecka et al., 1995; Kasuya 1995; Murdoch, 1995; Tilly, 1997; van Wezel et al., 1999a; Asselin et al., 2000).

Two independent light microscope examinations of bovine ovaries initially established different classifications of atresia (Rajakoski, 1960; Marion et al., 1968), and no 
attempt was made to link the two (Marion et al., 1968). This omission may have contributed to the unfortunate situation whereby many of the more recent studies into atresia and the modes of death of granulosa cells have not considered how these might relate to the different forms of atresia. Therefore, we have undertaken light and electron microscope examination of antral bovine follicles as they undergo early events of atresia. In the present study, we report different modes of atresia and show that a seminal report on follicular atresia (Rajakoski, 1960) mis-identified theca and granulosa cells and, hence, described one of the major types of atresia incorrectly. Marion et al. (1968) described this major type of atresia accurately but described incorrectly how this form of atresia originated. Here, we consider both of these studies in relation to our own and suggest that there are only two types of atresia of bovine antral follicles. The original observations have been extended to include the behaviour of macrophages and electron microscopy was used to identify cell types accurately. Our findings indicate that there is more than one mechanism of follicle atresia.

\section{Materials and Methods}

\section{Ovaries}

Bovine ovaries were collected and treated in a variety of ways (groups 1-5) to ensure that no artefact was being examined and that the appropriate techniques were being used to examine each particular aspect of follicle morphology. The ovaries comprising group 1 were examined by light microscopy after different fixation and processing regimens. Ovaries comprising group 2 were prepared for electron microscope examination only. Small follicles (group 3 ovaries) and large follicles (group 4) were harvested in such a way as to enable both immunohistochemical and electron microscope examinations to be conducted on the same follicles. Group 5 ovaries were collected from animals whose oestrous cycles had been controlled hormonally and monitored by ultrasonography. Ovaries from groups 1-4 were collected at a local abattoir in South Australia, within 20 min of death, from mixed breeds of Bos taurus cows, assessed visually as being nonpregnant.

Group 1. Twenty-four ovaries and 154 follicles were examined morphologically and the degree of atresia was assessed. One half of one ovary from each of 18 cows was fixed in either Bouin's solution ( $n=12$; for $24 \mathrm{~h}$; followed by washing in $70 \%(\mathrm{v} / \mathrm{v})$ ethanol for $24 \mathrm{~h}$ ) or in Carnoy's solution $(n=6 ; 60 \%(\mathrm{v} / \mathrm{v})$ ethanol, 30\% (v/v) chloroform and $10 \%(\mathrm{v} / \mathrm{v})$ acetic acid for $1.5 \mathrm{~h}$, followed by an overnight wash in $95 \%(\mathrm{v} / \mathrm{v})$ ethanol), and embedded in paraffin wax by standard methods. Sections $(5 \mu \mathrm{m}$ thickness) were cut from each paraffin wax-embedded ovary, deparaffinized in xylene, rehydrated in decreasing concentrations of ethanol, and stained with either haematoxylin and eosin or Verheoff van Giesson's trichrome stain. A slice of up to $5 \mathrm{~mm}$ thickness was cut through the centre of a further six ovaries and these slices were immersed immediately in Tissue-Tek OCT embedding compound (Miles Inc., Elkhart, IN) and snap-frozen; these blocks were stored at $-70^{\circ} \mathrm{C}$. The ovaries were selected on the basis of having few large antral follicles, as ice crystals forming in the follicular fluid of large follicles make it difficult to cut sections. Sections $(10 \mu \mathrm{m}$ thickness) from these snap-frozen ovaries were post-fixed in formalin for $20 \mathrm{~min}$ and stained with haematoxylin and eosin. The maximum and minimum diameters of each follicle in the section were measured and averaged to give an estimate of follicular size. The follicle diameters were measured from the basal lamina.

Group 2. Nine reproductive tracts were collected and one ovary per tract was perfusion-fixed for electron microscopy, as described below. A total of 23 follicles was examined in this way. The maximum and minimum diameters of each follicle in the section were measured and averaged to give an estimate of follicular size. The follicle diameters were measured from the basal lamina.

Group 3. Eighty-seven ovaries were transported to the laboratory on ice. Two follicles and adhering stroma (2$5 \mathrm{~mm}$ ) were dissected from each ovary; their diameter was measured and they were snap-frozen in OCT compound. The frozen follicles were bisected and one half was immersed in $2.5 \%(\mathrm{v} / \mathrm{v})$ glutaraldehyde, post-fixed in osmium tetroxide and embedded in epoxy resin (as described below). This portion was for subsequent light and electron microscope assessment, and the remaining tissue in OCT compound was retained for subsequent immunohistochemical examination.

Group 4. Large follicles (7-17 mm in diameter, one per ovary) were dissected from 30 ovaries and 18 were processed as per group 3 , and 12 were snap-frozen in OCT compound only.

Group 5. All cows were aged 2.5 years, nulliparous and of composite breeding: one-quarter Angus, one-quarter Hereford, one-quarter Pinzgauer and one-quarter Red Poll. Oestrus was synchronized by two i.m. injections of $\mathrm{PGF}_{2 \alpha}$ 10 days apart $(25 \mathrm{mg}$; Lutalyse; Pharmacia and Upjohn, Kalamazoo, MI). During the first follicular wave of the next oestrous cycle (between day 7 and day 10; day $0=$ oestrus) and once follicular dominance had been identified, all follicles $\geqslant 5 \mathrm{~mm}$ in diameter were aspirated using an Aloka $500 \mathrm{~V}$ ultrasound machine attached to a $5 \mathrm{MHz}$ transvaginal aspiration probe. This procedure initiated the synchronous emergence of a new wave of growing follicles, which was monitored by daily ultrasonography using a $7.5 \mathrm{MHz}$ transrectal probe attached to the Aloka 500V machine. Ovaries were collected when the dominant follicle of the ensuing wave was in one of three development stages: (i) growing: had reached dominance, was $>8 \mathrm{~mm}$ in diameter and had not reached plateau stage; (ii) plateau: had reached dominance, was $>8 \mathrm{~mm}$ in diameter and had static growth 
for at least the $24 \mathrm{~h}$ before ovary collection, but was still functionally dominant as determined by the absence of new growth of follicular development; or (iii) regressing: had reached dominance, but was starting to regress in size, and emergence of a new wave of follicular development was evident. Ovariectomies were performed by laparotomy via paralumbar incision and both ovaries were collected whenever possible. After ovariectomy, the ovaries were placed into cold Hank's balanced salt solution and transported immediately to the laboratory, where they were perfusion-fixed for electron microscopy as described below.

\section{Electron microscopy}

Portions of follicles from groups 3 and 4 (those fixed in glutaraldehyde only) were processed for electron microscopy. For groups 2 and 5, ovarian arteries were cannulated and the ovaries were flushed with $20 \mathrm{ml}$ medium (Earle's balanced salt solution for group 2 or Hank's solution for group 5) before flushing with $50 \mathrm{ml}$ $2.5 \%(\mathrm{v} / \mathrm{v})$ glutaraldehyde in buffer $(0.1 \mathrm{~mol}$ morpholinopropanesulphonic acid $\mathrm{I}^{-1}, \mathrm{pH} 7.3$, for group 2 or 0.1 mol phosphate buffer $\mathrm{I}^{-1}$ for group $5, \mathrm{pH} 7.3$ ) delivered over 5-10 $\mathrm{min}$. The ovaries were placed in fixative at $4^{\circ} \mathrm{C}$ overnight. Follicles were dissected from each ovary, cut in half and the cross-sectional diameter was measured using an ocular micrometer in the eyepiece of a dissecting microscope for follicles of groups 2, 3 and 5. Dominant and subordinate follicles from ovaries of group 5 were processed in the same way. For groups 2, 3, 4 and 5 small pieces of the follicle wall were taken, placed in fixative and stored at $4^{\circ} \mathrm{C}$. After several rinses with buffer to remove excess fixative, samples were post-fixed in $2 \%(\mathrm{v} / \mathrm{v})$ aqueous osmium tetroxide for $1 \mathrm{~h}$ at $4^{\circ} \mathrm{C}$, rinsed three times with distilled water ( $5 \mathrm{~min}$ each) and dehydrated by successive washes with acetone of increasing concentration to $100 \%$, on ice. After overnight infiltration with epoxy resin at room temperature, the specimens were embedded in fresh resin and cured at $60^{\circ} \mathrm{C}$ overnight. Sections ( $1 \mu \mathrm{m}$ thickness) were stained with $1 \%(\mathrm{v} / \mathrm{v})$ aqueous methylene blue for light microscope examination and $100 \mathrm{~nm}$ thick sections were stained with uranyl acetate and Reynold's lead citrate, and observed and photographed with a JEOL (Peabody, MA) CS1200 transmission electron microscope.

One hundred and fifty-four follicles from group 1 were examined, and 23 antral follicles $0.5-5.0 \mathrm{~mm}$ in diameter from group 2 were examined. One hundred and thirty-eight (91 healthy, 18 basal atretic and 29 antral atretic) from group 3 were examined, and 30 follicles from group 4 were examined. In group 5, 17 dominant follicles (six growing, five plateau and six regressing) and 50 subordinate follicles $>5 \mathrm{~mm}$ in diameter were examined.

\section{Immunohistochemistry}

Using ovaries of groups 3 and 4 in OCT compound (86 follicles were examined), macrophages and the follicular basal lamina were co-localized using an indirect immunofluorescence method. The human monocyte and macrophage marker CD68 was used to identify macrophages (clone EBM11; Dako Corporation, Carpinteria, CA). CD68 crossreacts with bovine macrophages (Gutierrez et al., 1999). The follicular basal lamina was identified using antibodies that recognize nidogen and entactin in bovine follicles (Dziadek et al., 1985; McArthur et al., 2000). Tissue sections (10 $\mu \mathrm{m}$ thickness) were cut from each of the frozen ovaries using a CM1800 Leica cryostat and collected on glass slides treated with $0.01 \%(\mathrm{v} / \mathrm{v})$ poly L-ornithine hydrobromide (P-4638; Sigma Chemical Co, St Louis, MO), and stored at $-20^{\circ} \mathrm{C}$ until use. Unfixed sections were dried under vacuum for $5 \mathrm{~min}$ followed by treatment with blocking solution (10\% normal donkey serum, D-9663; Sigma Chemical Co) in antibody diluent containing $0.55 \mathrm{~mol}$ sodium chloride $\mathrm{I}^{-1}$ and $10 \mathrm{mmol}$ sodium phosphate $\mathrm{I}^{-1}(\mathrm{pH}$ 7.1) for $20 \mathrm{~min}$. Incubation in primary antisera was conducted overnight (rabbit anti-nidogen (1:200) and mouse anti-human macrophage CD68 (1:200)). The secondary antibodies used were fluorescein (DTAF)conjugated AffiniPure donkey anti-rabbit IgG (711-015152; Jackson ImmunoResearch Laboratories Inc., West Grove, PA) together with biotin-SP-conjugated AffiniPure donkey anti-mouse IgG (715-066-151; Jackson ImmunnoResearch Laboratories Inc.) followed by Cy3-conjugated streptavidin (016-160-084; Jackson ImmunnoResearch Laboratories Inc.), all used at a concentration of 1:100 in hypertonic phosphate-buffered saline (hPBS) containing 0.274 mol sodium chloride $\mathrm{I}^{-1}, 5.4 \mathrm{~mol}$ potassium chloride $\mathrm{I}^{-1}$ and $10 \mathrm{mmol}$ sodium phosphate $\mathrm{I}^{-1}$. All incubations were carried out at room temperature in a humidified chamber and were washed (three $\times 5 \mathrm{~min}$ ) in hPBS after incubation with primary or secondary antibodies or streptavidin-conjugated reagent sections. Sections were mounted in mounting medium for fluorescence (S3023; Dako). Negative controls used non-immune serum to replace the primary antibody. No staining was observed with these controls.

\section{Light microscopic observations and photography}

Sections of bovine ovary stained with haematoxylineosin, Verhoeff van Giesson's trichrome stain or methylene blue were examined using an Olympus BX50 microscope, with or without Nomarski optics, and photographed with an Olympus SC35 camera attachment and Ilford FP-4 125 black and white film. Sections that were stained immunohistochemically were observed and photographed with an Olympus Vanox AHBT3 fluorescence microscope with Olympus C35AD-4 camera attachment and photographed with Kodak T-Max 400 black and white film.

\section{Statistical analyses}

Multiple regression analyses and Pearson chi-squared analyses were performed using Stata Statistical Software, Release 6.0 (Stata Corp, College Station, TX). Analyses of 
Table 1. The proportion of group 1 bovine follicles in each follicle category according to how the tissue was processed

\begin{tabular}{lccc}
\hline Processing & Antral atresia (\%) & Basal atresia (\%) & Healthy $(\%)$ \\
\hline Snap-frozen & $6 / 28$ & $5 / 28$ & $17 / 28$ \\
( $n=6$ ovaries) & $(21.4)$ & $(17.9)$ & $(60.7)$ \\
Bouin's fixed & $20 / 90$ & $22 / 90$ & $48 / 90$ \\
( $n=12$ ovaries) & $(22.2)$ & $(24.4)$ & $(53.3)$ \\
Carnoy's fixed & $9 / 36$ & $4 / 36$ & $23 / 36$ \\
( $n=6$ ovaries) & $(25)$ & $(11.1)$ & $(63.9)$ \\
Total & $35 / 154$ & $31 / 154$ & $88 / 154$ \\
& $(22.73)$ & $(20.13)$ & $(57.14)$ \\
\hline
\end{tabular}

The proportion is the number of follicles in each category divided by total number examined; also expressed as percentages in brackets.

There were no significant differences between processing methods, as assessed by Pearson chi-squared test.

the diameters of the follicles of each class required log transformation to normalize the data before regression analyses. The level of significance was $P<0.05$.

\section{Results}

\section{General}

Initial observations revealed two basic types of atresia on the basis of dead cells within the membrana granulosa detected by histology. Cell death involved either granulosa cells within the antral layers first, while the basal layers remained intact, or the reverse situation where death of the granulosa cells occurred in the basal layers, and the antral layers were still intact. These were designated as antral and basal atresia, respectively. Atresia morphology was independent of the tissue processing methods used. In group 1 ovaries, some tissues were snap-frozen and other tissues were fixed in Bouin's solution or Carnoy's solution and embedded in paraffin wax. The proportions of healthy, antral and basal atretic follicles was not significantly different (chi-squared analysis) among the three different types of fixative or processing methods (Table 1). The size distribution was also similar (multiple regression analyses) among the three fixatives (Table 2). The features of antral and basal atretic follicles are described in detail separately below.

\section{Antral atresia}

The number of layers of healthy granulosa cells in antral atretic follicles ranged from one to approximately eight, and in most cases the number of layers of granulosa cells in a single follicle was not uniform (Fig. 1a). Numerous pyknotic nuclei were present in either the layers of the membrana granulosa closest to the antrum (Fig. 1a) or in the antrum itself but in close proximity to the membrana granulosa (Figs 1a,b and 2). Cellular debris such as the remnants of mitochondrial membranes and cellular membranes was observed in association with the pyknotic nuclei in the
Table 2. Diameter of group 1 bovine follicles in each category according to how the tissue was processed

\begin{tabular}{|c|c|c|c|}
\hline \multirow[b]{2}{*}{ Processing } & \multicolumn{3}{|c|}{ Follicle diameter (mm) } \\
\hline & Antral atresia & Basal atresia & Healthy \\
\hline $\begin{array}{l}\text { Snap-frozen } \\
\text { ( } n=6 \text { ovaries) }\end{array}$ & $\begin{array}{c}4.19 \pm 0.71 \\
(6)^{*}\end{array}$ & $\begin{array}{c}1.82 \pm 0.44 \\
(4)\end{array}$ & $\begin{array}{c}1.59 \pm 0.26 \\
(18)\end{array}$ \\
\hline $\begin{array}{l}\text { Bouin's fixed } \\
\text { ( } n=12 \text { ovaries })\end{array}$ & $\begin{array}{c}2.56 \pm 0.25 \\
(20)\end{array}$ & $\begin{array}{c}1.64 \pm 0.17 \\
(22)\end{array}$ & $\begin{array}{c}2.40 \pm 0.39 \\
(48)\end{array}$ \\
\hline $\begin{array}{l}\text { Carnoy's fixed } \\
\text { ( } n=6 \text { ovaries) }\end{array}$ & $\begin{array}{c}3.36 \pm 0.92 \\
(9)\end{array}$ & $\begin{array}{c}1.45 \pm 0.26 \\
(4)\end{array}$ & $\begin{array}{c}1.71 \pm 0.23 \\
(23)\end{array}$ \\
\hline Total & $\begin{array}{c}3.04 \pm 0.30 \\
(35)\end{array}$ & $\begin{array}{c}1.64 \pm 0.13 \\
(30)\end{array}$ & $\begin{array}{c}2.06 \pm 0.23 \\
(89)\end{array}$ \\
\hline
\end{tabular}

Values are mean \pm SEM.

*Number of follicles is shown in brackets.

Antral atresia versus basal atresia: $P<0.01$; antral atresia versus healthy: $P<0.001$; basal atresia not significantly different from healthy; multiple regression analysis of log-transformed data.

antrum by electron microscopy. In contrast, irrespective of the number of layers of granulosa cells, the cells closest to the basal lamina were packed tightly (no large intercellular spaces) and the individual cells were apparently healthy (Figs 1 and 2). Pyknotic nuclei in these layers were rarely visible by either light microscopy (particularly intense staining with haematoxylin) or by electron microscopy (electron dense structures). The basal granulosa cells were generally rounded, although in very large follicles they were sometimes elongated (see Follicle growth parameters and morphology of group 5 section), with regular cell outlines and a high nuclear:cytoplasmic ratio. The basal granulosa cells contained a moderate number of mitochondria, which were rounded or tubular in cross-section, and a moderate amount of endoplasmic reticulum (Fig. 2). Lipid droplets (approximately $0.5 \mu \mathrm{m}$ ) were visible in supra-basal granulosa cells and occasionally in the apical region of basal cells, but rarely in the basal cytoplasm of granulosa cells lining the basal lamina. The follicular basal lamina of most antral atretic follicles was a single layer, sometimes thickened, with few convolutions, closely underlying the basal layer of granulosa cells (Fig. 2). Overall, the theca interna had a high cell:matrix ratio compared with the ovarian stroma. Fibroblasts present in the theca were spindle-shaped and were oriented parallel to the membrana granulosa (Figs $1 \mathrm{a}, \mathrm{b}$ and 2 ). In the theca interna, a 'thecal matrix' as observed by van Wezel et al. (1998) was present between the cells. This matrix was made up of threads of electron dense material resembling fragments of basal lamina. The theca interna was well-vascularized, with patent capillaries and larger blood vessels clearly evident (Fig. 1b).

\section{Basal atresia}

In contrast to antral atresia, basal atresia follicles showed destruction of the architecture of the most basal layer of 

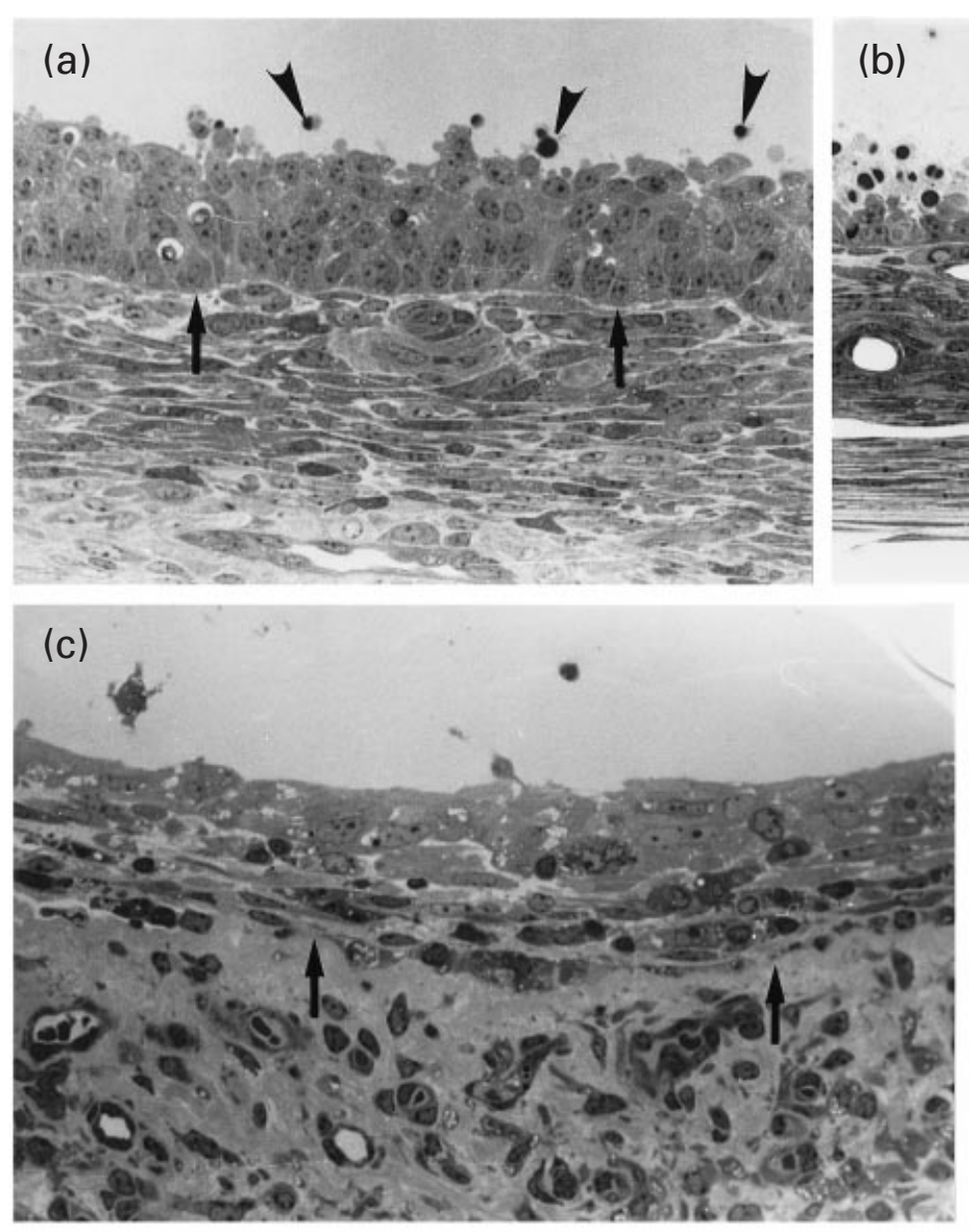
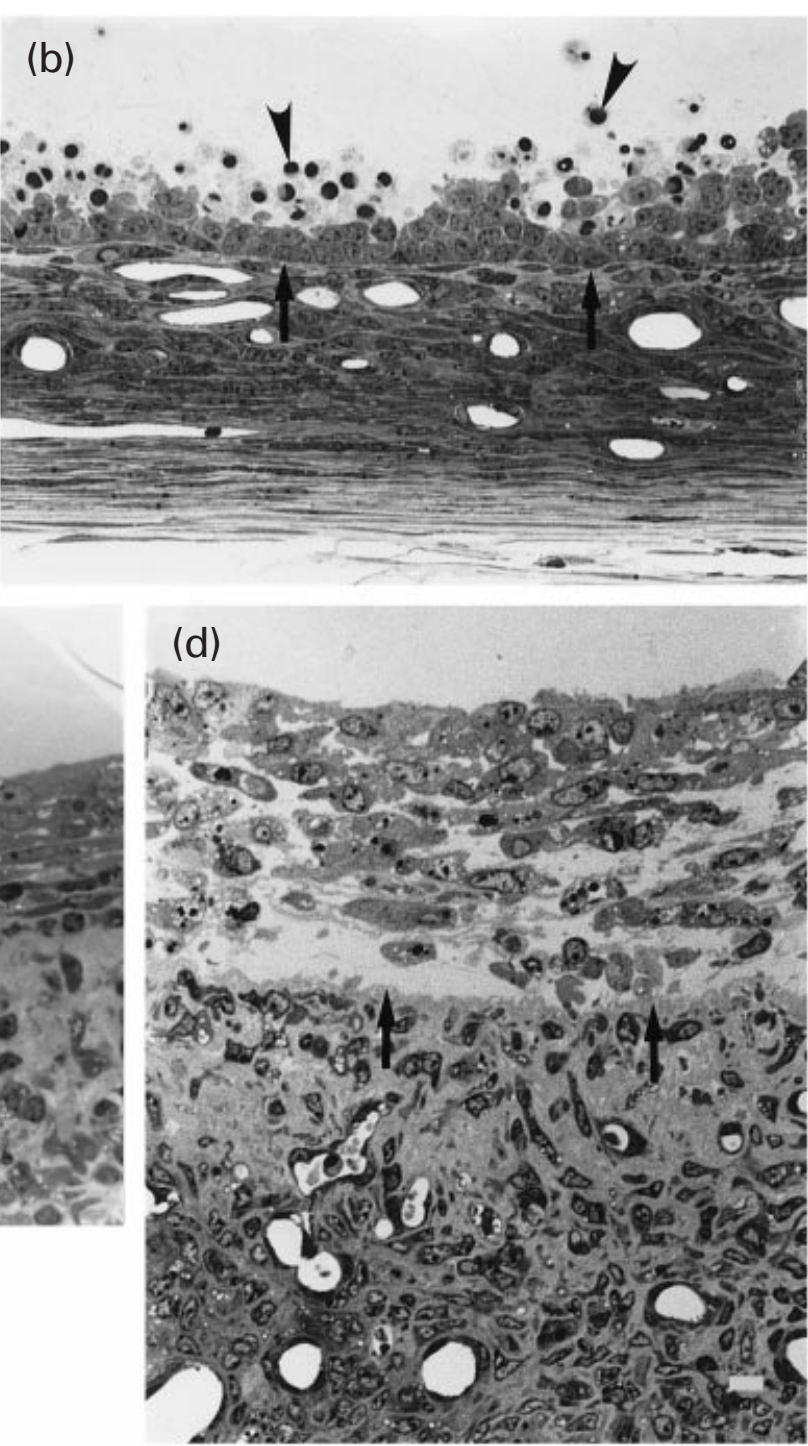

Fig. 1. Morphological features of antral atretic follicles: (a): early, $2.5 \mathrm{~mm}$ in diameter; (b): late, $3.0 \mathrm{~mm}$ in diameter; and basal atretic follicles (c): early, $2.0 \mathrm{~mm}$ in diameter; (d): late, $1.5 \mathrm{~mm}$ in diameter. Antral atretic follicles have the most basal layers of granulosa cells remaining intact. Cells in the antral layers have pyknotic nuclei (arrowheads), indicative of cell death. Cells in the theca lie parallel to the follicular basal lamina (arrows). In basal atretic follicles the granulosa cells close to the antrum are arranged tightly, whereas those in the most basal layers are arranged loosely. Many of the cells in the theca are oriented perpendicular to the basal lamina and there is more extracellular matrix between the cells compared with healthy follicles. These are epoxy sections stained with methylene blue. Scale bar represents $20 \mu \mathrm{m}$.

granulosa cells, whereas the most antral granulosa cells remained healthy and closely apposed to each other. There were very few pyknotic nuclei in the antrum or in the membrana granulosa (Figs 1c,d and 3). The cells closest to the antrum were often flattened, such that the overall antral surface of membrana granulosa appeared smooth and regular (Figs 1c,d and 3), in contrast to antral atretic follicles (Figs $1 a, b$ and 2). The granulosa cells immediately underneath this layer were more polygonal in shape. They were closely associated with each other and with the flattened cells closest to the antrum, and had small intercellular spaces only, thus retaining their integrity as a layer (Figs 1c,d and 3), also in contrast to the most superficial layer of many antral atretic follicles (Figs 1a,b and 2). The flattened granulosa cells close to the antrum contained morphologically normal nuclei and intact mitochondria and endoplasmic reticulum, whereas the middle layers of the membrana granulosa showed a gradation in terms of cellular architecture and cellular ultrastructure between those typical of the basal and the antral layers. The cells in the most basal layer of the membrana granulosa were separated from each other and 




Fig. 2. Electron micrograph of the membrana granulosa of an antral atretic follicle. Basal granulosa cells appear healthy and pyknotic nuclei are present in the follicular fluid (P1) and within the cytoplasm of granulosa cells (P2) after phagocytosis. Arrows: basal lamina. Scale bar represents $1 \mu \mathrm{m}$.

often from the basal lamina by large intercellular spaces (Figs 1c,d, 3 and 4). By electron microscopy the intercellular spaces were observed to contain abundant electron dense material similar to that found in follicular fluid (Figs 3 and 4). The cells were 'blebbing' (Fig. 4) and the nuclei were undergoing budding and formation of apoptotic bodies (Figs 3 and 4). Capillaries and macrophages had breached the basal lamina and were present in the basal area (Fig. 3, see below). Macrophages were clearly phagocytosing granulosa cell debris.
Basal lamina-like material continued to segregate the membrana granulosa from the theca and stroma; however, it was not organized into the single sheet typical of antral atretic follicles but was often convoluted in appearance. The basal lamina-like material sometimes spanned a zone up to $2 \mu \mathrm{m}$ wide. The theca interna was less cellular than either antral atretic (Fig. 4) or healthy follicles. This region stained pink with Verhoeff van Giesson's trichrome stain (not shown), which is indicative of collagen, and this was confirmed by electron microscopy, in which numerous filaments of banded 


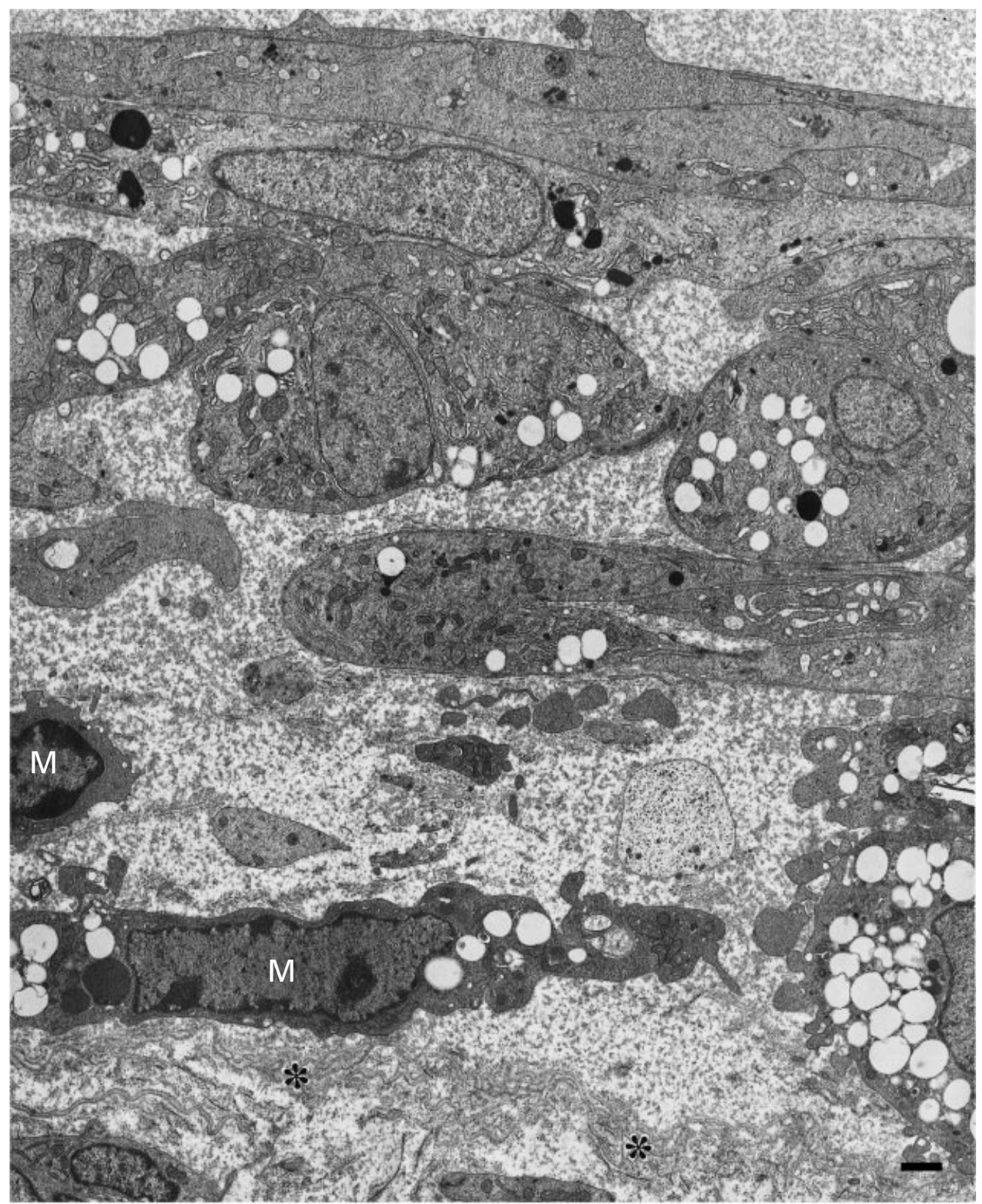

Fig. 3. Electron micrograph of the membrana granulosa of a basal atretic follicle. The most antral granulosa cells appear healthy and the basal lamina is highly convoluted (asterisks). M: macrophages. Scale bar represents $1 \mu \mathrm{m}$.

collagen were evident. Despite perfusion of the ovary with a balanced salt solution to flush out blood before fixation, red blood cells and other debris were frequently observed trapped within capillaries (Fig. 5), which is indicative of destruction of the vasculature before perfusion. The spindleshaped fibroblastic cells in the theca interna were either arranged randomly or oriented radially at right angles to the membrana granulosa (Figs 1c,d and 4), and in many of these cells the chromatin was clumped, staining more darkly with haematoxylin and more electron dense than in healthy cells.

\section{Involvement of macrophages in atresia}

Macrophages were immunolocalized as CD68-positive cells, and the follicular basal lamina was identified by localization of nidogen and entactin to determine the extent of macrophage involvement in the two types of atresia. Nidogen is also present in the basal laminae of blood vessels in the theca, but identified the follicular basal lamina clearly (McArthur et al., 2000). Electron microscope examination of follicles from groups $2-5$ was used to 


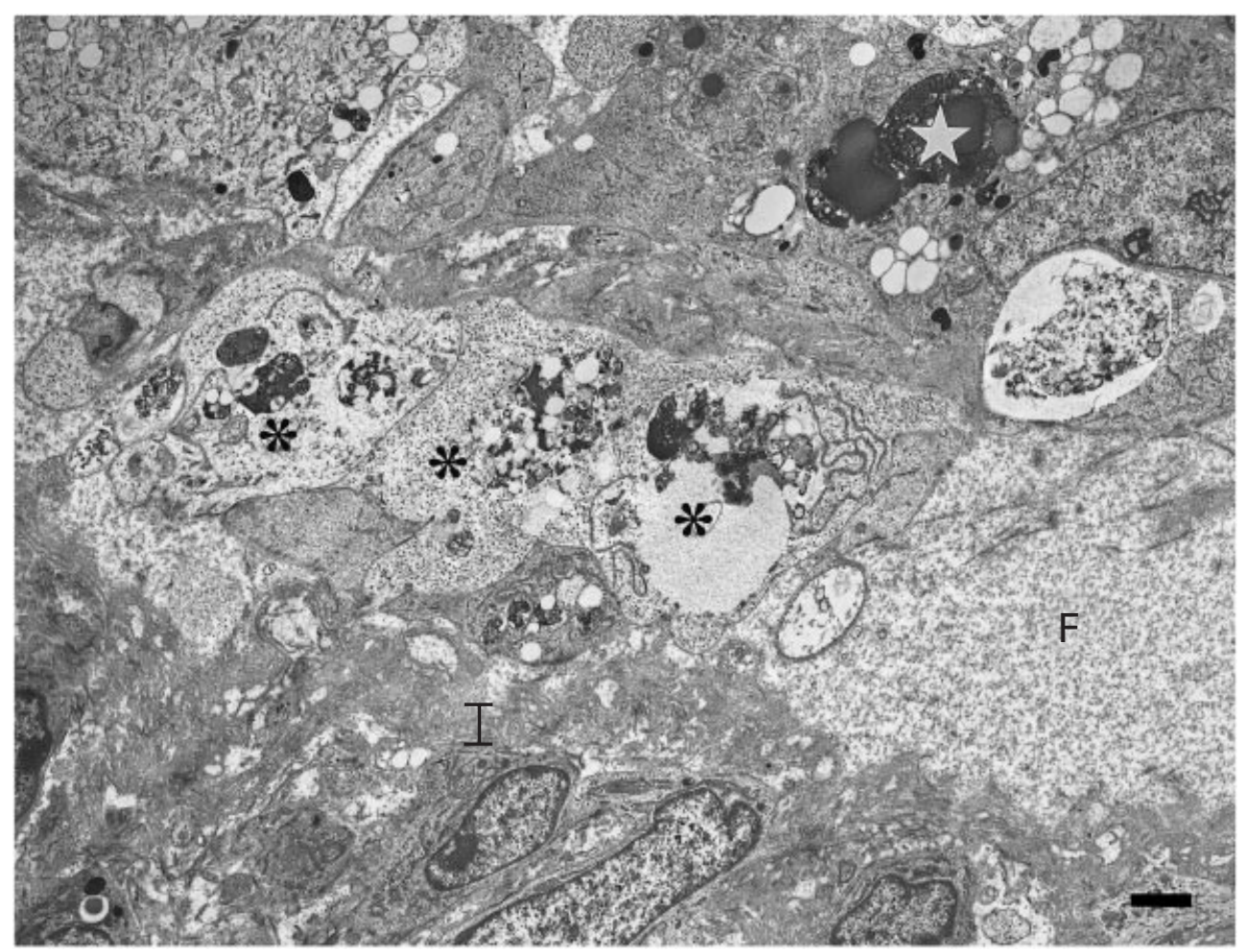

Fig. 4. Electron micrograph of the membrana granulosa of basal atretic follicle ( $3 \mathrm{~mm}$ in diameter). The basal lamina is highly convoluted (bracket) and exposed to the follicular fluid (F) where necrotic granulosa cells (asterisks) have detached. Star: granulosa cell undergoing apoptosis. Scale bar represents $2 \mu \mathrm{m}$.

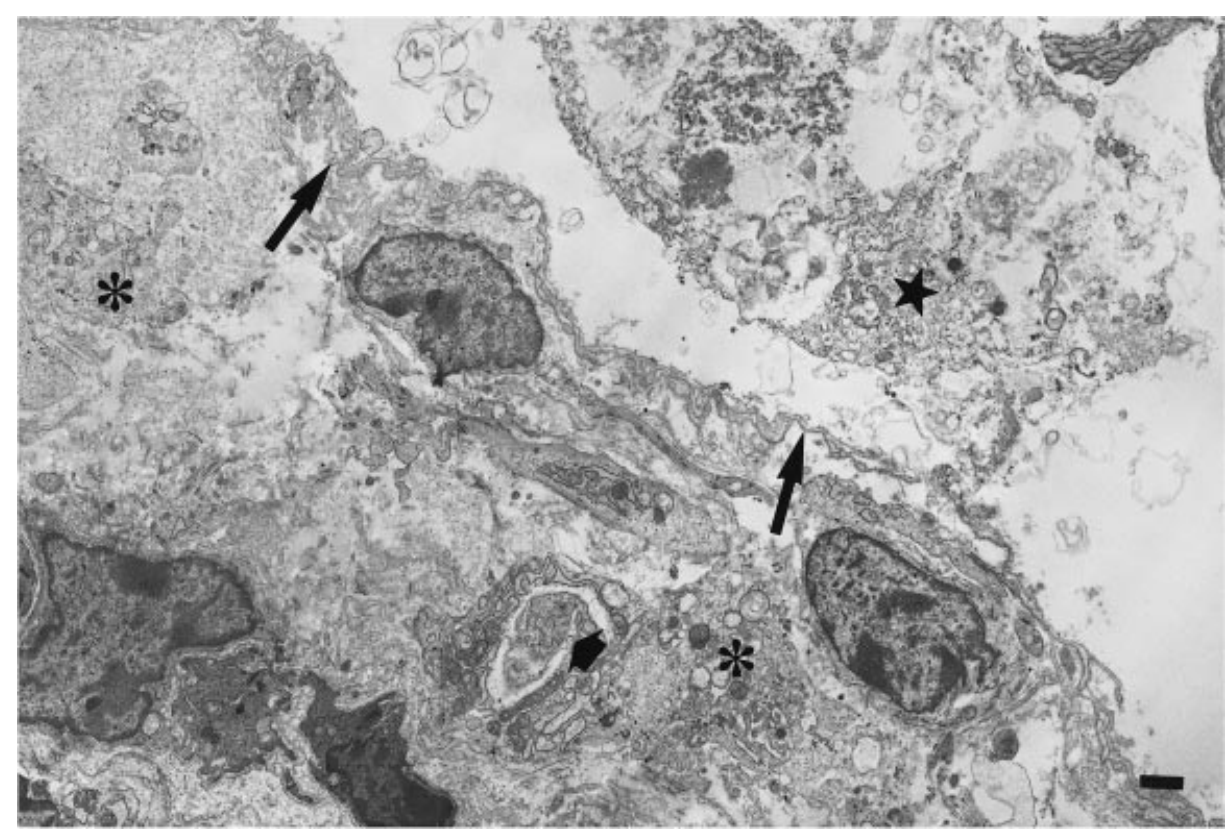

Fig. 5. Electron micrograph of the membrana granulosa of a basal atretic follicle $(3 \mathrm{~mm}$ in diameter). Cell debris is evident in the theca (asterisks) as well as the membrana granulosa (star). In addition, thecal capillaries contain cellular debris (arrowhead). Arrows: basal lamina. Scale bar represents $2 \mu \mathrm{m}$. 
confirm the observations. Macrophages often had an irregular cell outline due to the presence of many pseudopodia and those within the theca tended to be more stellate in shape compared with the more rounded macrophages within the membrana granulosa. Some nuclear chromatin condensation was evident and many cytoplasmic vacuoles were present within the cytoplasm (Fig. 3).

Group 3 follicles were classified arbitrarily as early, midor late atretic. Early atretic follicles had pyknotic nuclei in the antra, mid-atretic follicles had pyknotic nuclei in the antral layers and late atretic follicles had advanced pyknosis, such that only 1-2 layers of basal healthy cells remained. Basal atresia was classified as mid- or late, with early stages being difficult to differentiate from healthy tissue using light microscopy. Cell death in mid-basal atretic follicles occurred in the basal layer with partial expansion of matrix there. In late atresia, extensive basal areas of the former membrana granulosa were occupied by fluid, cell debris and macrophages.

In small healthy follicles (Fig. 6b), macrophages were observed within the membrana granulosa in only one of 18 healthy follicles $<5 \mathrm{~mm}$ in diameter (group 3) examined. In small antral atretic follicles (group 3), macrophages were also rare (one of eight early and one of 11 mid-stage antral atretic follicles), except in late antral atresia where macrophage penetration was more common (five of eight examined) (Fig. 7). In contrast to healthy and antral atretic follicles, all follicles undergoing basal atresia (Fig. 8) (four mid- and seven late stage follicles examined from group 3) had macrophages in the membrana granulosa. In large healthy follicles ( $n=21$ follicles $7-17 \mathrm{~mm}$ in diameter; group 4; Fig. $6 \mathrm{~d})$ and in large antral atretic follicles $(n=9$; group 4; Fig. 7h) no macrophages were observed by immunohistochemistry. In all atretic follicles, irrespective of size or type, there was a substantial recruitment of macrophages to the theca interna compared with healthy follicles (Figs 7 and 8).

\section{Frequency distribution of the follicle types}

The size-frequency distribution of group 1 follicles that were either healthy or undergoing antral or basal atresia is shown (Fig. 9). The atretic follicles constituted $42 \%$ of the antral follicles and were split approximately equally between antral and basal atresia. The mean size of antral atretic follicles was significantly larger than that of basal atretic follicles by about two-fold $(P<0.01$; multiple regression analysis of log-transformed data) and the sizefrequency distributions showed that significantly more large follicles were undergoing antral atresia. The group 3 follicles selected as being $2-5 \mathrm{~mm}$ in diameter were classified by light microscopy as being either healthy $(n=91)$, or antral $(n=29)$ or basal $(n=18)$ atretic. Group 4 follicles were selected as being $7-17 \mathrm{~mm}$ in diameter. They were healthy $(n=21)$ or antral atretic $(n=9)$, but none were basal atretic. Thus, although antral atresia was observed at all follicle sizes, basal atresia was confined to follicles $<5 \mathrm{~mm}$ in diameter.

\section{Follicle growth parameters and morphology of group 5}

Several parameters were measured to ensure that the follicles from each of the three subgroups were similar but just of different ages. Dominant follicles were harvested from the same ovary as previously aspirated follicles in four of six, two of four and six of seven for the growing, plateau or regressing follicle subgroups, respectively. Corpora lutea were present on the same ovary as the collected dominant follicle in five of six, one of four and four of seven for growing, plateau, or regressing follicle subgroups, respectively. Data on the growth rates for each of the follicles in the growing, plateau or regressing subgroups are summarized (Table 3). Follicles in each of the three groups were harvested at different intervals during the follicle wave (Table 3). The growth rates attained on reaching dominance (plateau and regressing subgroups) or before harvesting (growing subgroup) were similar for the three subgroups (Table 3), indicating that the three subgroups of follicles followed similar growth trajectories as they assumed dominance. The sizes of the follicles at harvesting were similar among the subgroups (Table 3), but clearly the growth just before collection was significantly different (Table 3). Follicles in the growing subgroup were clearly increasing in size, those in the plateau subgroup were static in size and those in the regressing subgroup were shrinking (Table 3). Thus, clearly the follicles in each of the three groups were similar except for different stages of dominance or regression.

Growing dominant follicles were healthy with many granulosa layers (Fig. 10a; Table 3). Dominant plateau follicles were either atretic (two of four) or healthy (Fig. 10b). All growing and plateau follicles had rounded basal granulosa cells. Of the follicles in the regressing group, one was healthy, one was in early antral atresia, two were in mid-antral atresia and three were in late antral atresia. The three follicles classified as being in late antral atresia had flattened basal cells and the others had rounded basal cells. This phenotype may be due to rapid expansion of the follicular antrum during growth, causing the cells to flatten as the membrana granulosa expands sideways to accommodate antrum expansion. The number of layers of granulosa cells also decreased from the growing to the plateau stage (Fig. 10c; Table 3), indicating that the rate of antrum expansion was outpacing the net rate of granulosa cell replication at this stage of follicle growth. Antral atresia in these larger dominant follicles did have some minor differences from that of smaller follicles. As larger follicles can have fewer layers of granulosa cells compared with smaller follicles (van Wezel et al., 1999b) it was not surprising that there was sometimes not a complete layer of healthy basal cells when the follicles entered antral atresia. In addition, these follicles were unmistakably in antral atresia as there were no gaps between the basal cells or 

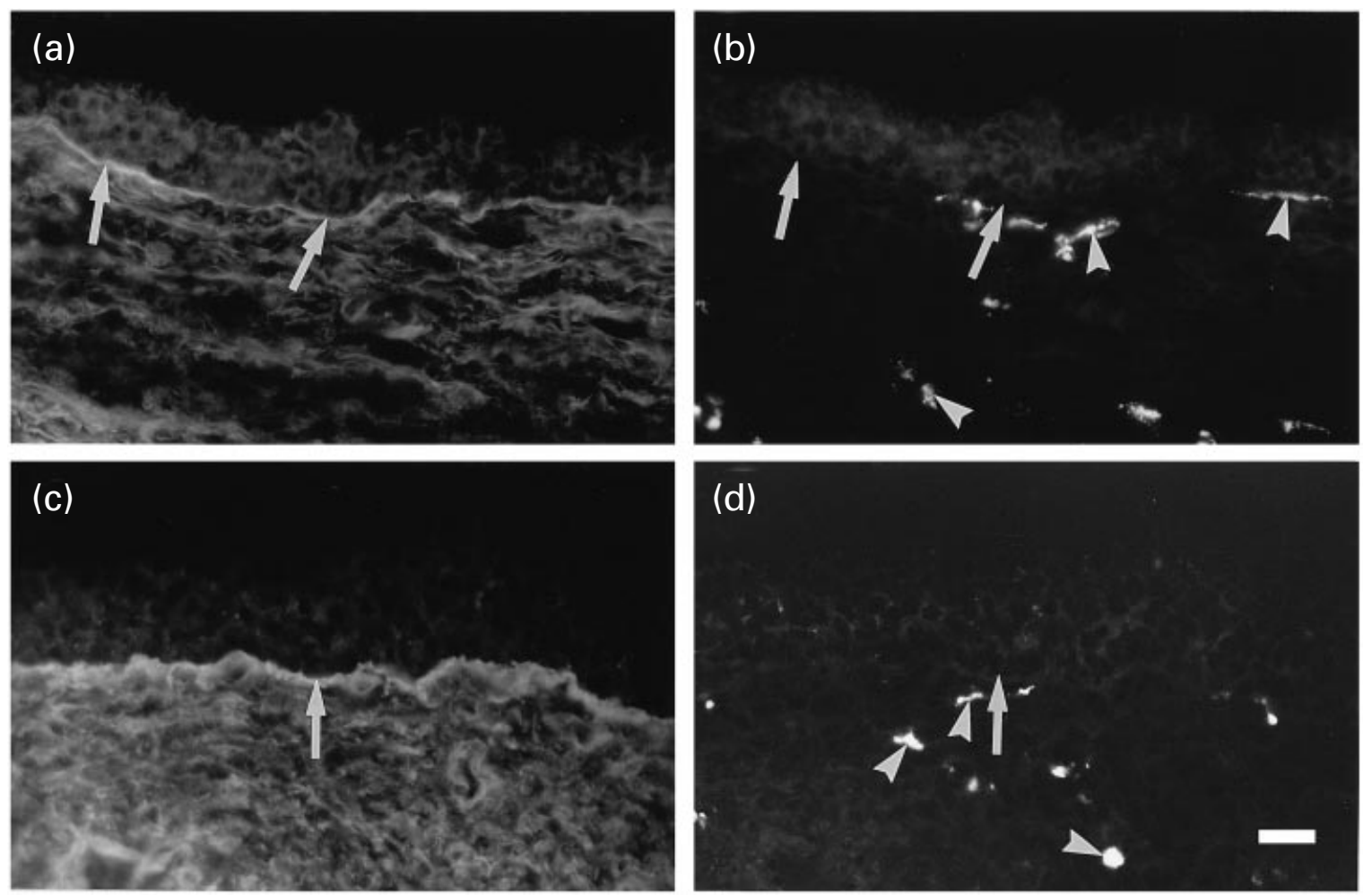

Fig. 6. Immunohistochemical colocalization of $(a, c)$ nidogen and $(b, d)$ CD68 in small $(a, b ; 3.5$ mm in diameter) and large (c,d; $8 \mathrm{~mm}$ in diameter) antral follicles. The position of the basal lamina is indicated by arrows. Arrowheads: CD68-positive cells. Scale bar represents $2 \mu \mathrm{m}$.

macrophage infiltration as occurs in basal atresia. In addition, a number of other follicles that had participated in the wave and that grew to $>5 \mathrm{~mm}$ in diameter $(n=50)$ were examined, of which 40 were healthy (pyknotic nuclei were rarely visible), seven were antral atretic, two were basal atretic and one had flattened granulosa cells. A random sample of atretic follicles $<5 \mathrm{~mm}$ in diameter was of either type.

\section{Discussion}

We have completed a histological, ultrastructural and immunohistochemical study of bovine antral follicles and have been able to simplify the classification of atresia into two types. Antral atretic follicles were characterized by initial destruction of the layers of the membrana granulosa closest to the antrum, with numerous pyknotic nuclei in the most antral layers and in the antrum, while the most basal cells remain intact. In basal atretic follicles the reverse pattern of destruction occurred. However, pyknotic nuclei were rarely observed; instead, apoptotic bodies were common in the basal granulosa cells. Macrophages were not present in the membrana granulosa of healthy follicles or in antral atretic follicles until the very late stages of degeneration. In contrast, macrophages had breached the follicular basal lamina of basal atretic follicles and were phagocytosing the dying granulosa cells. Although antral atresia was observed in all sizes of antral follicle, basal atresia was confined almost exclusively to smaller follicles $(<5 \mathrm{~mm}$ in diameter).

There have been two comprehensive morphological studies on atresia of bovine antral follicles, which have been used subsequently to establish biochemical criteria for assessing atresia. A summary of the terms used in these studies is presented (Table 4). In the first study, Rajakoski (1960) described four classes of bovine follicular atresia, two of which were related primarily to preantral and small antral follicles and involved early oocyte degeneration. The other two classes were common in antral follicles 1-6 mm in diameter and involved the degeneration of the follicular wall. These last two classes were termed 'obliterative' and 'cystic'. 'Obliterative atresia' was categorized further into atresia of the 'first degree, second degree and third degree' (Table 4). Rajakoski (1960) described only the light microscopic morphology of these follicles, and illustrated their size-frequency distributions in ovaries. On the basis of the size-frequency distributions, which are very similar to those of the present study and the description of the 'first degree of obliterative atresia', this type of atresia appears to be the same as antral atresia described in the present study. 

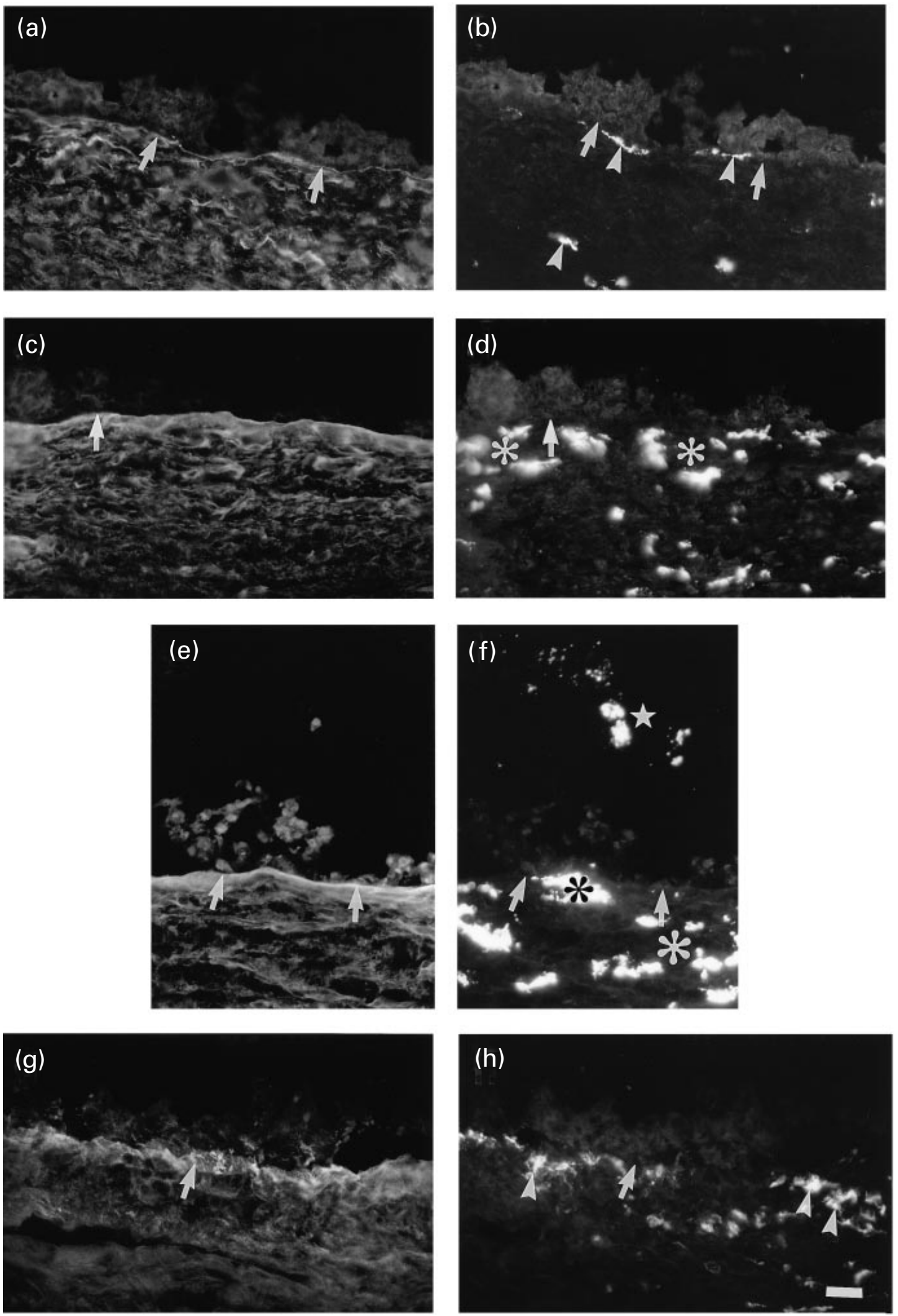

Fig. 7. Immunohistochemical colocalization of $(\mathrm{a}, \mathrm{c}, \mathrm{e}, \mathrm{g})$ nidogen and $(\mathrm{b}, \mathrm{d}, \mathrm{f}, \mathrm{h})$ CD68 in antral atretic follicles at different stages. CD68positive cells are present in the theca in increasing numbers as atresia progresses (compare $b$ and $d$ ), and in the antrum only of some follicles in late atresia (f). (a,b): early antral atresia, follicle $3.5 \mathrm{~mm}$ in diameter; $(c, d)$ : mid-antral atresia, follicle $3 \mathrm{~mm}$ in diameter; (e,f): late antral atresia, follicle $4 \mathrm{~mm}$ in diameter; $(\mathrm{g}, \mathrm{h})$ : late antral atresia, follicle $8 \mathrm{~mm}$ in diameter. Arrows: basal lamina; asterisks and arrowheads: CD68-positive cells in the theca; star: CD68-positive cells in the antrum. Scale bar represents $2 \mu \mathrm{m}$. 
Table 3. Characteristics of bovine follicles of group 5

\begin{tabular}{|c|c|c|c|c|c|c|c|}
\hline Follicle type & $\begin{array}{l}\text { Number } \\
\text { of follicles }\end{array}$ & $\begin{array}{l}\text { Follicle } \\
\text { diameter } \\
(\mathrm{mm})\end{array}$ & $\begin{array}{c}\text { Time }>5 \mathrm{~mm} \\
\text { (days) }\end{array}$ & $\begin{array}{l}\text { Maximal } \\
\text { growth rate } \\
\left(\mathrm{mm} \mathrm{day}^{-1}\right)^{*}\end{array}$ & $\begin{array}{l}\text { Growth rate } \\
\text { before harvest } \\
\left(\mathrm{mm} \mathrm{day}^{-1}\right)^{\dagger}\end{array}$ & $\begin{array}{c}\text { Membrana } \\
\text { granulosa } \\
\text { thickness }(\mu \mathrm{m})\end{array}$ & $\begin{array}{l}\text { Number of } \\
\text { granulosa } \\
\text { cell layers }\end{array}$ \\
\hline Growing & 6 & $9.1 \pm 0.6^{\mathrm{a}}$ & $3.7 \pm 0.7^{a}$ & $1.2 \pm 0.4^{\mathrm{a}}$ & $1.2 \pm 0.4^{\mathrm{a}}$ & $57.5 \pm 3.2^{\mathrm{a}}$ & $6.7 \pm 0.7^{a}$ \\
\hline Plateau & 4 & $9.9 \pm 0.5^{a}$ & $7.5 \pm 1.7^{\mathrm{a}}$ & $1.0 \pm 0.6^{\mathrm{a}}$ & $0.0 \pm 0.0^{b}$ & $38.0 \pm 22.2^{\mathrm{ab}}$ & $4.8 \pm 1.4^{\mathrm{a}}$ \\
\hline Regressing & 7 & $9.0 \pm 0.9^{a}$ & $8.3 \pm 0.9^{a}$ & $1.5 \pm 0.5^{\mathrm{a}}$ & $-0.6 \pm 0.1^{\mathrm{c}}$ & $27.6 \pm 5.6^{b}$ & $4.0 \pm 0.7^{a}$ \\
\hline
\end{tabular}

Values are mean \pm SEM.

Growing: follicle had reached dominance, was $>8 \mathrm{~mm}$ in diameter and had not reached plateau stage; plateau: follicle had reached dominance, was $>8 \mathrm{~mm}$ in diameter and had static growth for at least the $24 \mathrm{~h}$ before ovary collection, but was still functionally dominant as determined by the absence of new growth of follicular development; regressing: follicle had reached dominance, but was starting to regress in size, and emergence of a new wave of follicular development was evident.

*Maximal growth rate for growing follicles was the maximum recorded before they were harvested in the growth phase, whereas growth rate for the other groups was the maximum they attained in the 2 days before reaching maximum diameter.

${ }^{+}$Follicle growth rate for the 2 days before follicle collection.

${ }^{a b c}$ Different superscripts indicate significant differences within columns $(P<0.05 ;$ ANOVA; SNK).
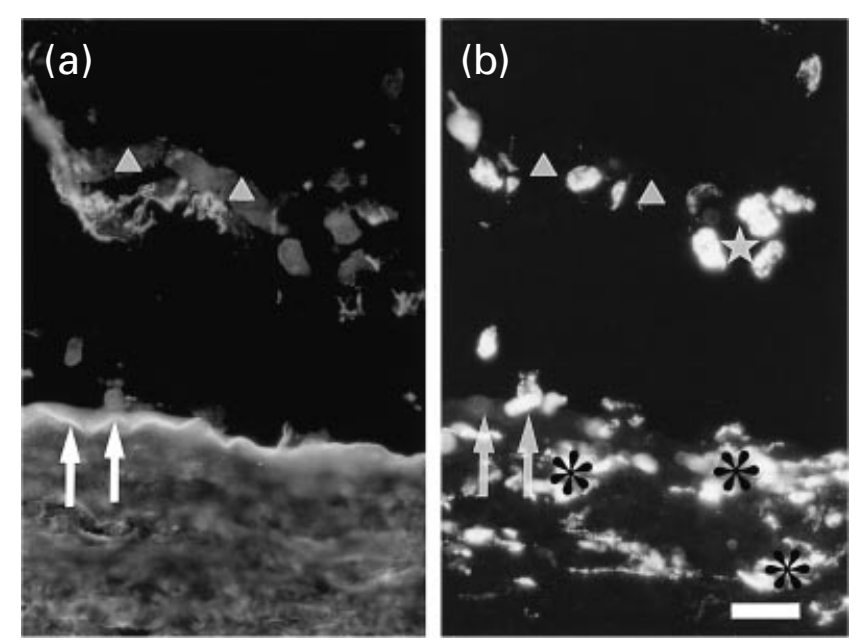

Fig. 8. Immunohistochemical colocalization of (a) nidogen and (b) CD68 in basal atretic follicles (4 mm in diameter). CD68 immunopositive cells are present in large numbers within the theca (asterisks) and antrum (star). Arrows: basal lamina; triangles: granulosa cells. Scale bar represents $2 \mu \mathrm{m}$.

Follicles in the 'second degree of obliterative atresia' (Rajakoski, 1960) were described by Rajakoski as: '...the granulosa has completely degenerated and no pyknotic nuclei are present in the lumen...' and '...thecal connective tissue cells extend inwards and begin to fill the lumen...'. This description of second degree atresia is different from that of our basal atretic follicles, but we believe that these follicles are the same, on the basis of the follicle size-frequency distributions. Thus, it appears that Rajakoski (1960), using a light microscope, mis-identified granulosa cells as invading thecal cells.

Marion et al. (1968) also undertook a classification of follicular atresia but these authors made no attempt to reconcile their data with those of Rajakoski (1960). The present study does this. The 'contracting or obliterative'

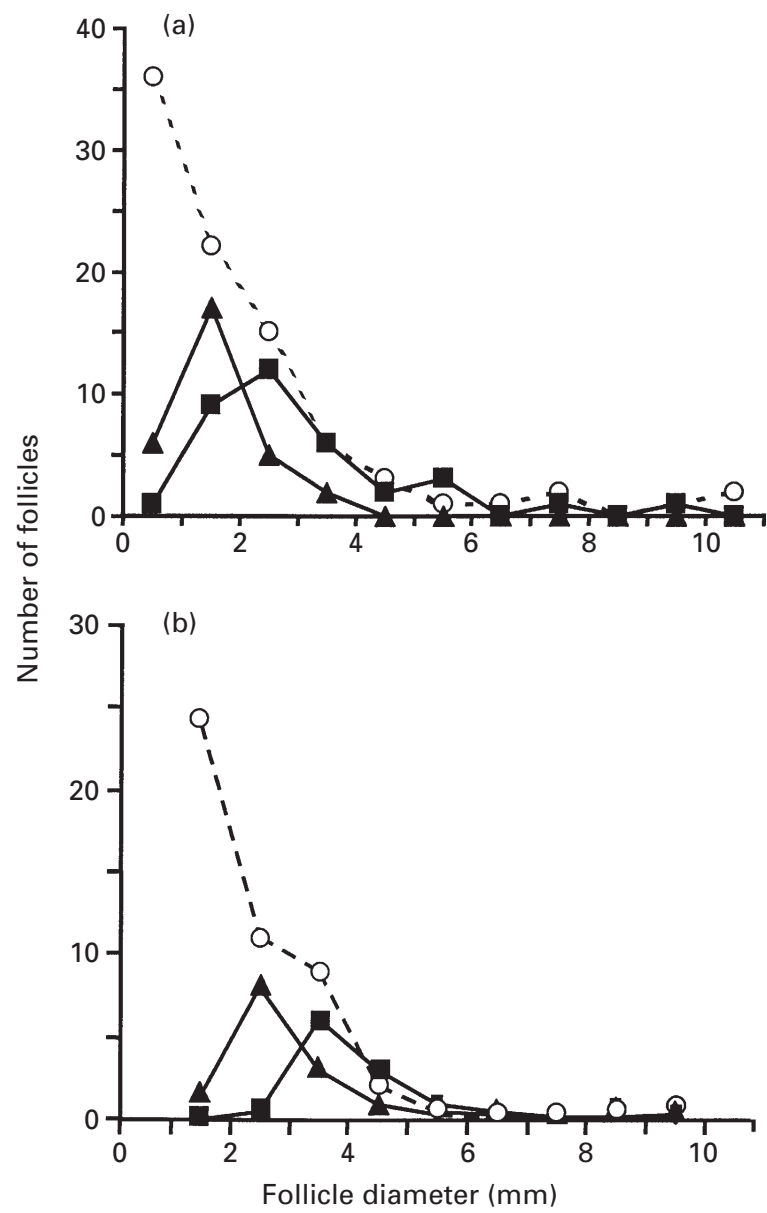

Fig. 9. (a) Size distributions of healthy $(\bigcirc ; n=89)$, antral atretic $(\mathbf{\square} ; n=35)$ and basal atretic $(\mathbf{\Delta} ; n=30)$ follicles from group 1. Follicles were measured to the nearest $0.1 \mathrm{~mm}$. The number of follicles in each $1 \mathrm{~mm}$ size range was determined and plotted at the mid-size of each category (for example, 0.5, 1.5 and $2.5 \mathrm{~mm}$ ). (b) Size distributions of healthy $(\bigcirc)$, and grade I ( $\mathbf{\square})$ and II ( $\mathbf{\Delta})$ obliterative atretic follicles redrawn from Rajakoski (1960). 
atresia was reported to comprise $80 \%$ of the 'definite atresia' category, and was illustrated and described by Marion et al. (1968). It is the same as antral atresia described in the present study and is similar to the description of 'obliterative first degree atresia' by Rajakoski (1960). Cystic follicular atresia also appears to be a late form of antral atresia described in the present study and agrees with the description of cystic atresia by Rajakoski (1960).

Marion et al. (1968) also described the single, and some places double, cellular layers of granulosa cells of these follicles and assumed that these follicles had begun to expand on atresia. From the observations of dominant follicles in the present study it is clear that the number of layers of granulosa cells decreases as follicles enlarge to reach a plateau. Rodgers et al. $(1999,2001)$ also discussed this concept. The number of granulosa cell layers is both a function of the net rate of granulosa cell replication and the rate of the antrum expansion. Thus, the 'string of pearls' description used by Marion et al. (1968) and others since, arises by a reduction in the number of layers of granulosa cells as the antrum expands during follicular growth, not atresia.

The 'late atresia' category was illustrated (Fig. 32 from Marion et al., 1968) and described as having 'an expanded stratum granulosum'. This description and illustration fits that of our basal atretic follicles. However, Marion et al. (1968) assumed that this is a late phase of atresia and concluded that it formed from shrinkage of a very large follicle (> $10 \mathrm{~mm}$ in diameter), thus accounting for the many layers of loosely packed cells in these follicles. With current information on follicle dynamics (Fortune, 1991; Ginther et al., 1996) we now know that this could not be the case. However, these follicles do fit the phenotype of basal atretic follicles observed in the present study. In addition, this type of atresia was never observed in large (> $5 \mathrm{~mm}$ in diameter) follicles. Thus, it is concluded that there appear to be only two basic processes of atresia in bovine antral follicles.

When cells die in different regions of the bovine membrana granulosa they show different morphological characteristics, representing different biochemical mechanisms (van Wezel et al., 1999a; present study). In a recent study of cell death in atresia (van Wezel et al., 1999a), it was observed that pyknotic nuclei occurred in the antral region and more centrally in the membrana granulosa. The DNA of the antrally situated cells was not heavily degraded, nor did they have the classic features of apoptosis or necrosis, leading us to suggest that this mode of death had more in common with terminal differentiation (van Wezel et al., 1999a). In contrast, the pyknotic nuclei in the central regions were often condensed into a crescent shape and had very degraded DNA (van Wezel et al., 1999a). Many of these had been phagocytosed as whole nuclei with surrounding cytoplasm by neighbouring cells. The morphology of the phagocytosing cells in the previous study of antral atretic follicles was that of granulosa cells, and not macrophages, as also confirmed in the present study. In the present study, it was observed that in basal atresia the cells
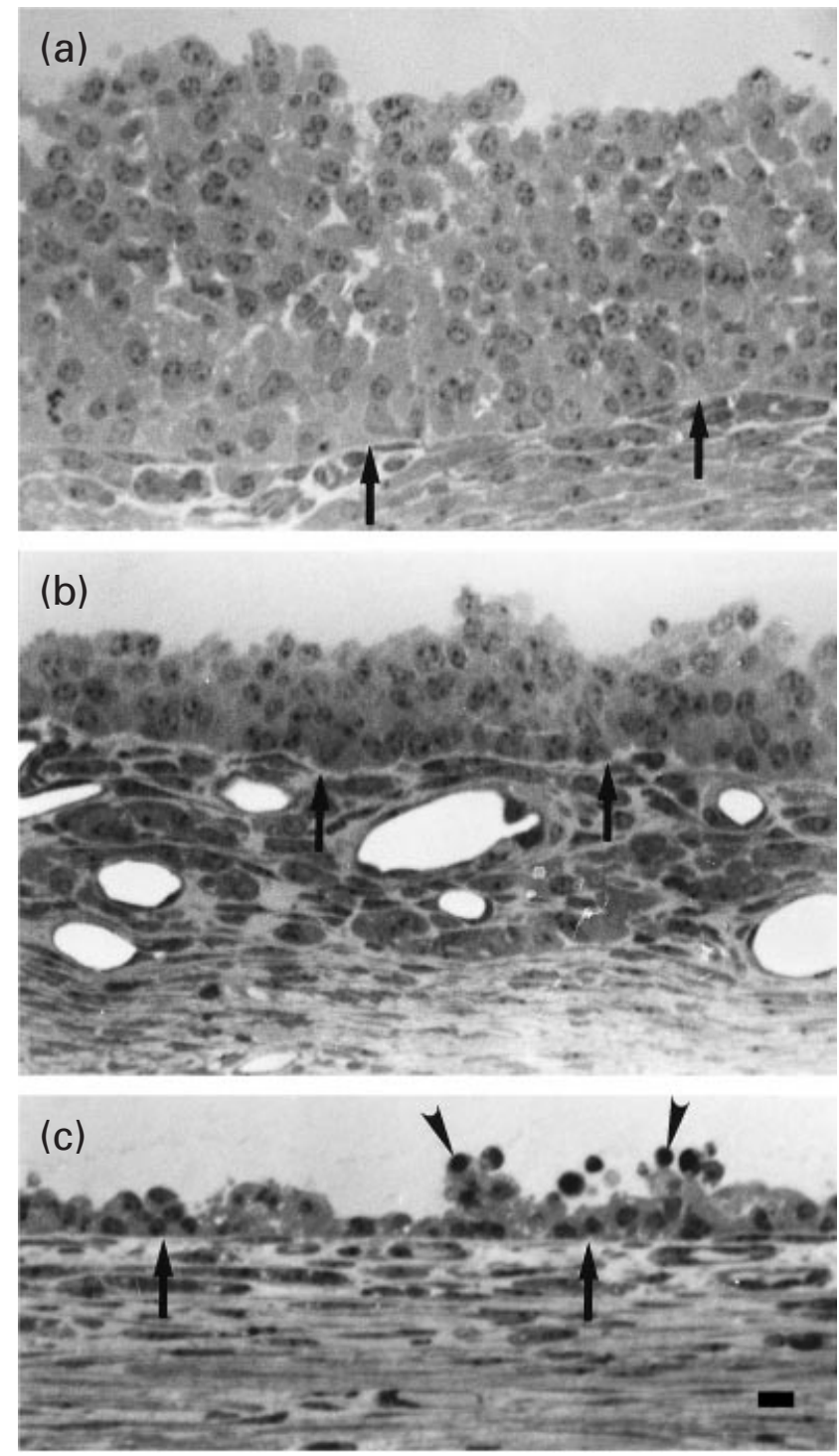

Fig. 10. Morphological features of (a) growing $(10.5 \mathrm{~mm}$ in diameter), (b) plateau (10 $\mathrm{mm}$ in diameter) and (c) regressing (10.8 $\mathrm{mm}$ in diameter) dominant follicles in group 5. These are $1 \mu \mathrm{m}$ epoxy sections stained with methylene blue. Arrows: basal lamina; arrowheads: pyknotic nuclei. Scale bar represents $2 \mu \mathrm{m}$.

in the basal region showed classic features of apoptosis, with budding of the nuclei and cell preceding phagocytosis as well as macrophage infiltration. It is not clear why there should be a regional variation in the features of cell death and, hence, in the biochemical processes leading to cell death in the membrana granulosa.

Two other studies (H. F. Irving-Rodgers and R. J. Rodgers, unpublished) of basal and antral atresia also showed considerable differences between the characteristics of these processes. In the membrana granulosa of small healthy or antral atretic follicles $(<5 \mathrm{~mm}$ in diameter) there 
Table 4. Comparison of terms used to describe atresia by Rajakoski (1960), Marion et al. (1968) and classification in the present study

\begin{tabular}{|c|c|c|c|c|}
\hline \multirow[b]{2}{*}{ Present study } & \multicolumn{2}{|c|}{ Rajakoski (1960) } & \multicolumn{2}{|c|}{ Marion et al. (1968) } \\
\hline & Major class & Sub class & Major class & Sub class \\
\hline Artefact & & & Definite atresia & Collapsing ${ }^{b}$ \\
\hline Early antral atresia & & & Early atresia & \\
\hline Antral atresia & Obliterative atresia & First degree & Definite atresia & $\begin{array}{l}\text { Contracting or obliterative } \\
\text { atresia }\end{array}$ \\
\hline Advanced antral atresia & Cystic atresia & & Definite atresia & Cystic \\
\hline Basal atresia & Obliterative atresia & Second degree & $\begin{array}{l}\text { Late atresia (previously } \\
\text { large follicles, } 10 \mathrm{~mm} \text { in } \\
\text { diameter, shrunk to small } \\
\text { follicles, } 2 \mathrm{~mm} \text { in diameter) }\end{array}$ & \\
\hline
\end{tabular}

Not considered ${ }^{\mathrm{a}} \quad$ Obliterative atresia Third degree

Not considered ${ }^{\mathrm{a}}$

Definite atresia

Luteinized-cystic follicles

aThe very advanced stages of follicular atresia and regression and follicular cysts were not considered in the present study.

bThe collapsing atresia had no indications of any cellular death. The follicles had collapsed and the follicle wall had buckled inwards. This phenotype can be produced by puncturing the follicle and, thus, we consider that 'collapsing atresia' is not atresia at all.

was no expression of cholesterol side-chain cleavage cytochrome P450 (P450XIA1) or 3 $\beta$-hydroxysteroid dehydrogenase. However, with basal atresia, $3 \beta$-hydroxysteroid dehydrogenase was expressed in these follicles. Cholesterol side-chain cleavage cytochrome P450 was also expressed in half of them, indicating that the granulosa cells of these basal atretic follicles synthesize progesterone during the course of atresia. In fact, in an early report by Grimes et al. (1987), bovine follicles $>5 \mathrm{~mm}$ in diameter were classified as either healthy or atretic. Approximately $6 \%$ of the follicles were classified as 'atretic-luteinized' and described as having elongated and hypertrophied granulosa cells and a disorganized theca. Grimes et al. (1987) found that progesterone concentrations were four- to eight-fold greater in the follicular fluid of these follicles than in healthy or follicles classified as atretic by standard criteria (antral atresia description in the present study). This would be expected if they were in fact the same as follicles described as basal atretic in the present study.

In another study of follicles, a particular unique extracellular matrix was observed, which was composed of at least nidogen, perlecan and some laminin and type IV collagen chains (H. F. Irving-Rodgers and R. J. Rodgers, unpublished), expressed not as a basal lamina, but as plaques of matrix between the granulosa cells. This matrix never appeared during the process of antral atresia but was present between the remaining healthy antral cells of basal atretic follicles. These very disparate behavioural differences between cells in the two types of atresia also support the concept that different mechanisms are involved in the two types of atresia.

In conclusion, bovine follicles can undergo one of two types of atresia depending on where the granulosa cells die first. Antral atresia fits the classic description of atresia as many of us know it, with pyknotic nuclei that first appear nearest the antrum with more appearing progressively towards the basal lamina as atresia develops. Basal atresia appears very differently: cells die first near the basal lamina and cell death progresses towards the antrum. When the basal cells die they have the classic apoptotic features where the nucleus buds and apoptotic bodies are phagocytosed, and so pyknotic nuclei are seldom observed. This type of atresia also involves upregulation of steroidogenic enzymes in the remaining live antrally situated cells, and early invasion of the membrana granulosa by macrophages from the theca. As this latter type of atresia is common in bovine follicles $<5 \mathrm{~mm}$ in diameter and was mis-identified in earlier studies, the subsequent studies investigating changes in steroid hormone concentrations on atresia clearly need to be repeated and our standard biochemical methods of assessing atresia need to re-evaluated.

This work was supported by the Flinders Medical Centre Research Foundation, the Flinders University of South Australia and the National Health and Medical Research Council of Australia. This work was also supported by USDA CRGO 9037240-5724 and appropriated funding of the State of Nebraska. The authors would like to thank A. Esterman and P. Hakendoff for their expert assistance in statistical analyses, and G. Gobe for her initial assistance in interpreting electron micrographs. The authors would like to thank $M$. Krupa for assistance in immunohistochemistry and M. Master for assistance with tissue collection and processing for electron microscopy. The technical assistance of D. Clopton, K. Pearson and C. Toombs in ovary collection is much appreciated.

\section{References}

Asselin E, Xiao CW, Wang YF and Tsang BK (2000) Mammalian follicular development and atresia: role of apoptosis Biological Signals and Receptors 9 87-95

Blondin P, Dufour M and Sirard MA (1996) Analysis of atresia in bovine follicles using different methods: flow cytometry, enzyme-linked 
immunosorbent assay, and classic histology Biology of Reproduction 54 $631-637$

Byskov AG (1978) Follicular atresia. In The Vertebrate Ovary pp 533-562 Ed. RE Jones. Plenum Press, New York

Derecka K, Kalamarz H and Ziecik AJ (1995) Does apoptosis occur during follicular atresia in the follicle walls of the porcine ovary? Reproduction in Domestic Animals $3032-35$

Dziadek M, Paulsson M and Timpl R (1985) Identification and interaction repertoire of large forms of the basement membrane protein nidogen EMBO Journal 4 2513-2518

Fortune JE (1991) Ovarian follicular growth and development in mammals Biology of Reproduction 50 225-232

Ginther OJ, Wiltbank MC, Fricke PM, Gibbons JR and Kot K (1996) Selection of the dominant follicle in cattle Biology of Reproduction $\mathbf{5 5}$ 1187-1194

Greenwald GS and Terranova PF (1988) Follicular selection and its control. In The Physiology of Reproduction pp 387-445 Eds E Knobil, JD Neill, LL Ewing, GS Greenwald, CL Markert and DW Pfaff. Raven Press, New York

Grimes RW, Matton P and Ireland JJ (1987) A comparison of histological and non-histological indices of atresia and follicular function Biology of Reproduction 37 82-88

Gutierrez M, Forster FI, McConnell SA, Cassidy JP, Pollock JM and Bryson DG (1999) The detection of CD2+, CD4+, CD8+, and WC1+ T lymphocytes, B cells and macrophages in fixed and paraffin embedded bovine tissue using a range of antigen recovery and signal amplification techniques Veterinary Immunology and Pathology 71 321-334

Hirshfield AN and Midgley AR (1978) Morphometric analysis of follicular development in the rat Biology of Reproduction 19 597-605

Hughes FM, Jr and Gorospe WC (1991) Biochemical identification of apoptosis (programmed cell death) in granulosa cells: evidence for a potential mechanism underlying follicular atresia Endocrinology 129 2415-2422

Irving-Rodgers HF and Rodgers RJ (2000) Ultrastructure of the follicular basal lamina of bovine ovarian follicles and its relationship to the membrana granulosa Journal of Reproduction and Fertility 118 221-228

Jolly PD, Tisdall DJ, Heath DA, Lun S and McNatty KP (1994) Apoptosis in bovine granulosa cells in relation to steroid synthesis, cyclic adenosine 3'5'-monophosphate response to follicle-stimulating hormone and luteinizing hormone, and follicular atresia Biology of Reproduction $\mathbf{5 1}$ 934-944

Kasuya K (1995) The process of apoptosis in follicular epithelial cells in the rabbit ovary, with special reference to involvement by macrophages Archives of Histology and Cytology 58 257-264
Kruip TA and Dieleman SJ (1982) Macroscopic classification of bovine follicles and its validation by micromorphological and steroid biochemical procedures Reproduction, Nutrition and Development 22 465-473

McArthur ME, Irving-Rodgers HF, Byers S and Rodgers RJ (2000) Identification and immunolocalisation of decorin, versican, perlecan, nidogen, and chondroitin sulfate proteoglycans in bovine small ovarian follicles Biology of Reproduction 63 913-924

Marion GB, Gier HT and Choudary JB (1968) Micromorphology of the bovine ovarian follicular system Journal of Animal Science 27 451-465

Murdoch WJ (1995) Programmed cell death in preovulatory ovine follicles Biology of Reproduction 53 8-12

Palumbo A and Yeh J (1994) In situ localization of apoptosis in the rat during follicular atresia Biology of Reproduction 51 888-895

Rajakoski E (1960) The ovarian follicular system in sexually mature heifers with special reference to seasonal, cyclical and left-right variations Acta Endocrinologica 34 (Supplement 52) 6-68

Rodgers RJ, Lavranos TC, van Wezel IL and Irving-Rodgers HF (1999) Development of the ovarian follicular epithelium Molecular and Cellular Endocrinology 151 171-179

Rodgers RJ, Irving-Rodgers HF, van Wezel IL, Krupa M and Lavranos TC (2001) Dynamics of the membrana granulosa during expansion of the ovarian follicular antrum Molecular and Cellular Endocrinology 171 41-48

Tilly JL (1997) Apoptosis and the ovary: a fashionable trend or food for thought? Fertility and Sterility 67 226-228

van Wezel IL, Rodgers HF and Rodgers RJ (1998) Differential localization of laminin chains in the bovine follicle Journal of Reproduction and Fertility 112 267-278

van Wezel IL, Dharmarajan AM, Lavranos TC and Rodgers RJ (1999a) Evidence for alternative pathways of granulosa cell death in healthy and slightly atretic bovine antral follicles Endocrinology 40 2602-2612

van Wezel IL, Krupa M and Rodgers RJ (1999b) Development of the membrana granulosa of bovine antral follicles: structure, location of mitosis and pyknosis, and immunolocalization of involucrin and vimentin Reproduction, Fertility and Development 11 37-48

Received 30 March 2001.

First decision 2 May 2001.

Accepted 7 June 2001. 